\title{
ACÚMULO DE SERAPILHEIRA EM QUATRO TIPOS DE VEGETAÇÃO NO ESTADO DE GOIÁS
}

Nauara Lamaro Lima ${ }^{*}$, Carlos de Melo e Silva-Neto ${ }^{2}$, Francine Neves Calil ${ }^{3}$, Kellen Rabello de Souza ${ }^{1}$, Douglas Cézar de Moraes ${ }^{4}$

${ }^{1}$ Mestranda do Programa de Pós-graduação em Agronomia, Escola de Agronomia, Universidade Federal de Goiás.

${ }^{2}$ Doutorando do Programa de Pós-graduação em Agronomia, Escola de Agronomia, Universidade Federal de Goiás.

${ }^{3}$ Professora do Curso de Engenharia Florestal e do Programa de Pós-graduação em

Agronomia, Escola de Agronomia, Universidade Federal de Goiás.

${ }^{4}$ Engenheiro Florestal, Escola de Agronomia, Universidade Federal de Goiás.

*nauaralamaro@gmail.com

Recebido em: 08/09/2015 - Aprovado em: 14/11/2015 - Publicado em: 01/12/2015

DOI: http://dx.doi.org/10.18677/Enciclopedia_Biosfera_2015_068

\section{RESUMO}

A serapilheira é o principal componente que mantém a produtividade da floresta, com a ciclagem dos nutrientes. Este trabalho teve por objetivo quantificar o acúmulo de serapilheira e suas compartimentalizações em quatro tipos de vegetação, sendo uma área de Cerrado sentido restrito, uma mata de galeria, um plantio de eucalipto e outro de pinus. Em cada área foram coletadas 30 amostras aleatórias de serapilheira utilizando uma moldura de madeira de $25 \mathrm{~cm} \times 25 \mathrm{~cm}$. As amostras foram pesadas secas e depois separadas em compartimentos (folha/acículas, galhos, casca, material reprodutivo e miscelânea). A fração folhas/acículas é a que mais contribui para a formação da serapilheira, seguido dos galhos, devido à senescência e reposição de novas folhas. O pinus possui maior quantidade total de serapilheira, devido ao plantio ser mais antigo e a decomposição de acículas serem mais lenta. As formações florestais apresentam 0 mesmo padrão quantidade $e$ compartimentalização de serapilheira.

PALAVRAS-CHAVE: Biomassa, ciclagem de nutrientes, compartimentalização.

\section{LITTER ACCUMULATION IN FOUR TYPES OF VEGETATION IN THE STATE OF GOIÁS}

\begin{abstract}
Litter is the main component that maintains forest productivity through nutrients cycling. This study had as objective to quantify accumulated litter and its compartmentalization in four vegetation types: "Strictosensu Savanna", permanent preservation area (PPA), Eucalyptus stand and Pinus stand. In each area, 30 (thirty) samples were randomly collected with a wooden frame $(25 \mathrm{~cm} \times 25 \mathrm{~cm})$. Samples were weighed and then separated in compartments: leaves/needles, branches, bark, reproductive material and miscellany. The fraction leaves/needles is the one that contributes the most for litter formation, followed by branches, due to senescence
\end{abstract}


and new leaves formation. Pinus has the highest total amount of litter, because the stand is old and needles decomposition is slow. Forest formations show the same litter quantity and compartmentalization pattern.

KEYWORDS: Biomass, nutrient cycling , compartmentalization

\section{INTRODUÇÃO}

Em ecossistemas florestais, a serapilheira é a responsável pelo constante equilíbrio da produtividade florestal, com ciclagem de nutrientes de compostos, pois é formada segundo PIOVESAN et al. (2012) por folhas, galhos, troncos, material reprodutivo- flores, frutos e sementes, insetos, animais e resíduos fecais. Sua importância é devido a funções ecológicas, pois funciona como amortecedor da água da chuva, evitando erosão, além de reter essa água, reduzindo a temperatura do solo, disponibiliza nutrientes para a ciclagem de nutrientes (SCHUMACHER et al., 2004), além de servir como nicho para a mesofauna e microrganismos (CALDEIRA, et al, 2007).

FIGUEIREDO-FILHO et al. (2003), ressaltam que a quantidade de serapilheira acumulada varia com relação as condições edafoclimáticas e com o tipo de vegetação existente na floresta. A latitude e altitude também influenciam a deposição de serapilheira, assim como o relevo e o estágio de desenvolvimento que se encontram as plantas.

A decomposição da serapilheira, em especial do componente folha, que além de ser em maior quantidade, possui uma relação equilibrada $\mathrm{C} / \mathrm{N}$ e celulose/lignina, é fonte de nutrientes, principalmente carbono, para o solo (CALDEIRA et al., 2008). E essa relação $\mathrm{C} / \mathrm{N}$ influencia a velocidade da decomposição do material favorecendo os microrganismos decompositores (DICKOW et al., 2009). A floresta se mantém viva com este ciclo equilibrado de trocas de nutrientes no sistema, desta forma a qualidade do solo é diretamente proporcional à qualidade dos nutrientes que antes continha a serapilheira.

O estudo da serapilheira permite ter o conhecimento do quanto a floresta esta produzindo, o quanto decompõe de matéria, qual a fase fenológica das espécies e o processo de ciclagem de nutrientes (CALDEIRA et al., 2007). Com essas informações tem-se uma base da situação futura da floresta, podendo assim buscar soluções caso futuro para melhorar as condições da floresta (BORÉM \& RAMOS, 2002). Assim o objetivo deste é quantificar o acúmulo de serapilheira e seus compartimentos formadores (galhos, folhas ou acículas, material reprodutivo, casca e miscelânea) sobre o solo em quatro diferentes áreas, sendo uma Mata de Galeria, um Cerrado Sentido Restrito, um plantio de eucalipto e outro de pinus no Estado de Goiás.

\section{MATERIAL E MÉTODOS}

\section{Caracterização das áreas de estudo}

\section{Área de Preservação Permanente e Área de Cerrado Sentido Restrito}

A área está localizada na Floresta Nacional de Silvânia - FLONA. A FLONA possui área total de 487 hectares; está localizada na zona rural do município de Silvânia - Goiás, situada sob as coordenadas geográficas 1639'26"S e 4836'16" e uma altitude média de 900 m. O clima, seguindo a classificação de Köppen (PEELL 
et al. 2007) é Aw, possuindo um clima tropical e uma estação seca bem definida, com temperatura média anual de $21,95^{\circ} \mathrm{C}$.

O relevo é predominantemente plano e o solo é do tipo Latossolos, composto por Latossolo Vermelho-Escuro e Latossolos Vermelho-Claro (ICMBIO, 2015). Nesta área, as amostras foram realizadas nas fitofisionomias de Cerrado Sentido Restrito e mata de galeria.

\section{Plantio de Eucalipto}

A área de eucalipto pertence à empresa Muda Forte, localizada no município de Goianápolis, Goiás. A espécie plantada é o Eucalyptus urograndis, com cinco anos de idade. O espaçamento utilizado é de três $x$ dois metros. O solo é o classificado como Latossolo, e o clima é Aw, tropical quente predominante em Goiás.

\section{Plantio de Pinus}

O plantio possui 34 anos e pertence à empresa Vale do Rio Grande Reflorestamento LTDA., localizado no município de Catalão, Goiás. A área total é de aproximadamente 50 hectares e a espécie é o Pinus oocarpa. A classificação climática de Köppen é Aw, do tipo tropical quente, com chuvas no verão e outono. $O$ Solo é do tipo Latossolo-Vermelho-amarelo (PRADO \& SILVA, 2011; FERREIRA \& CARDOSO, 2013). A localização das três áreas podem ser visualizadas no mapa digital:

https://drive.google.com/file/d/0ByQNaWHmeZ15Tm1wZFZuUTR6VG8/view?usp=sh aring

\section{Coleta e preparação das amostras}

Com o auxílio de uma moldura de madeira de $25 \mathrm{~cm} \times 25 \mathrm{~cm}\left(0,0625 \mathrm{~m}^{2}\right)$, realizou-se 30 coletas aleatórias no interior das áreas de estudo, seguindo por base a metodologia de KLEINPAUL et al. (2003). Nesses locais de amostragem, a camada de serapilheira foi coletada até o solo mineral ficar exposto. O material coletado em seguida foi armazenado em sacos de papel identificados e posteriormente levados ao Laboratório de Alometria e Inventário Florestal da Universidade Federal de Goiás (UFG).

No laboratório, as amostras foram secas em estufa de circulação e renovação de ar, a $70^{\circ} \mathrm{C}$ por aproximadamente 72 horas, até atingir peso constante. Após a secagem da serapilheira realizou-se a pesagem com balança digital $(0,1 \mathrm{~g})$ do material de cada amostra individual, e depois foi realizada a separação, com auxílio de pinças, em frações distintas: folhas ou acículas, galhos, casca, material reprodutivo e miscelânea, sendo cada fração pesada novamente.

\section{Cálculo da biomassa de serapilheira acumulada}

A partir dos dados provenientes da coleta de serapilheira, foi estimada a quantidade total de matéria seca (serapilheira) depositada sob o piso florestal. Foi calculada a porcentagem de cada fração da serapilheira e obtida a média das amostras de cada área estudada. A estimativa por unidade de área (hectare) foi realizada por extrapolação da massa seca, com base na área da moldura $(0,0625$ $\mathrm{m}^{2}$ ) (VIEIRA \& SCHUMACHER, 2010). 


\section{RESULTADOS E DISCUSSÃO}

A quantidade total de serapilheira acumulada sobre o solo na área de preservação permanente (APP) foi de $10.098,00 \mathrm{~kg} \mathrm{ha}^{-1}$ (Tabela 1), sendo, as folhas responsáveis pela maior parte de biomassa, apresentando $73,11 \%$, seguido de galhos $20 \%$, casca $3,75 \%$, material reprodutivo $1,74 \%$ e miscelânea com $1,02 \%$ (Figura 1). Na área de Cerrado Sentido Restrito a serapilheira acumulada foi de $10.291,20 \mathrm{~kg}$, sendo esta, composta por $73,47 \%$ de folhas, $3,68 \%$ de casca, $18,13 \%$ galhos, $2,49 \%$ de material reprodutivo e $2,23 \%$ de miscelânea.

Sobre o solo em plantio de eucalipto a serapilheira acumulada foi de $9.518,40$ $\mathrm{kg} / \mathrm{ha}$, sendo $83,98 \%$ composto de folhas, $3,33 \%$ de casca, $11,43 \%$ de galho, $1,17 \%$ de material reprodutivo e $0,09 \%$ de miscelânea. No plantio de pinus a produção total de $15.267,2 \mathrm{~kg} / \mathrm{ha}$, composto por $77,72 \%$ de acículas, $4,94 \%$ de casca, $3,42 \%$ de galho, $13,82 \%$ de material reprodutivo e $0,1 \%$ de miscelânea.

TABELA 1. Quantidade $(\mathrm{kg})$ em cada compartimentalização de serapilheira nas áreas de Mata de Galeria, Cerrado Sentido restrito, Plantio de Eucalipto e de Pinus. .

\begin{tabular}{ccccc}
\hline $\mathbf{K g} / \mathrm{Ha}$ & $\begin{array}{c}\text { Mata de } \\
\text { Galeria }\end{array}$ & Cerrado SR & Eucalipto & Pinus \\
\hline Folhas (acícula) & 7.384 & $7.561,60$ & $7.993,60$ & $11.865,6$ \\
Casca & 379,2 & 379,2 & 316,8 & 753,6 \\
Galho & $2.057,60$ & $1.865,60$ & $1.088,00$ & 521,6 \\
Material reprodutivo & 174,4 & 256 & 112 & 2.110 \\
Miscelânia & 102,4 & 228,80 & 8,00 & 16 \\
\hline
\end{tabular}

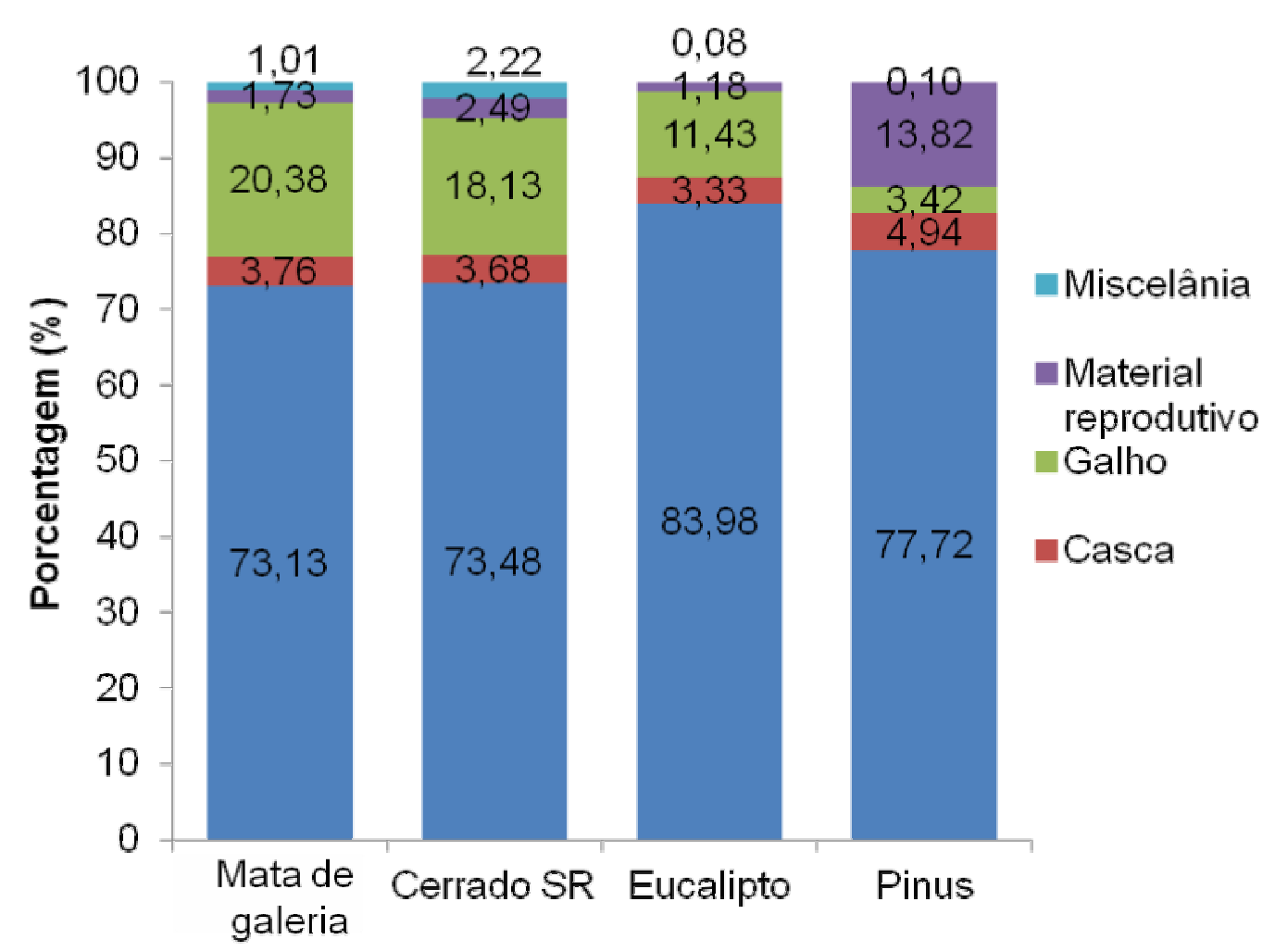

FIGURA 1: Compartimentalizações da serapilheira na Mata de Galeria, Cerrado Sentido Restrito, Eucalipto e Pinus. 
Em um estudo realizado por MAMAN et al., (2007) sobre a produção e acúmulo de serapilheira e decomposição foliar em mata de galeria no município de Nova Marilândia e cerradão no município de Tangará da Serra, no sudoeste de Mato Grosso, resultou em uma produção contínua de serapilheira durante o ano. Com mata de galeria apresentando uma serapilheira acumulada de $68,9 \%$ de folhas, seguida pela fração de galhos com $28,8 \%$, frutos e sementes com $2,1 \%$ e flores $0,2 \%$. Na área de Cerradão a serapilheira acumulada apresentou $70,3 \%$ da fração folhas, $27,7 \%$ de galhos, $1,8 \%$ de frutos e sementes e $0,2 \%$ de flores.

SOUZA et al., (2011), realizando estudo em área de cerrado sentido restrito e cerradão no Parque Municipal do Bacaba, Nova Xavantina-MT, registrou $83 \%$ de folhas, $9,41 \%$ ramos finos, $4,94 \%$ flores/frutos e $2,57 \%$ de outros materiais no cerrado sentido restrito. No cerradão obtiveram $77,54 \%$ de folhas, $9,51 \%$ ramos finos, e 6,13 de outros materiais. KLEINPAUL et al. (2003), no Campus da Universidade Federal de Santa Maria, RS, sobre acúmulo de serapilheira em povoamentos de eucaliptos plantado com 12 anos de idade resultou em 11,63 Mg $\mathrm{ha}^{-1}$ de valor total, predominando a fração galhos com $39 \%\left(4,53 \mathrm{Mg} \mathrm{ha}^{-1}\right)$ seguido pela fração folhas com $36,2 \%$, casca com $12,1 \%$, miscelânea com $9,5 \%$ e estruturas reprodutivas com 3,4\%. A maior porcentagem apresentada pelos galhos pode ser explicada pelo fato do povoamento já ser adulto e ocorrer desrama natural.

CORRÊA (2011) em estudo sobre a ciclagem de nutrientes em povoamento de Eucalyptus dunnii com um ano e meio, no Bioma Pampa obteve uma deposição de aproximadamente $4,1 \mathrm{Mg} \mathrm{ha}^{-1} \mathrm{ano}^{-1}$ de serapilheira, com uma média de $93 \%$ de folhas, $6 \%$ de miscelânea, e $1 \%$ de galho grosso. A fração de miscelânea foi composta por material reprodutivo, galhos finos e casca.

Segundo POGGIANI \& SCHUMACHER (2000), é crescente a deposição de serapilheira até as árvores alcançarem idade de maturidade, quando há o fechamento das copas. Após esta fase é observado um ligeiro decréscimo ou a estabilidade na deposição de serapilheira.

PIOVESAN et al. (2012) em estudo de deposição de serapilheira em floresta de Pinus taeda L. de oito anos, localizado no município de Quedas do Iguaçu, PR, tiveram resultado de $7,1 \mathrm{Mg} \mathrm{ha}^{-1}$, sendo a maior parte formada por acículas com $95,6 \%$, galhos finos com 2,3\% e miscelânea com 2,1\%. Em um estudo realizado por KLEINPAUL et al. (2003), sobre acúmulo de serapilheira em povoamentos de pinus plantado no Campus da Universidade Federal de Santa Maria, RS, com 21 anos obtiveram valor total de serapilheira acumulada no solo de $21,92 \mathrm{Mg} \mathrm{ha}^{-1}$, sendo o compartimento mais relevante as acículas com $57,2 \%\left(12,53 \mathrm{Mg} \mathrm{ha}^{-1}\right)$, a fração casca contribuiu com $2,5 \%$, galhos com $16,7 \%$, estruturas reprodutivas com $15,9 \%$ e miscelânea com $7,7 \%$.

Valores mais elevados de biomassa de serapilheira em plantios de Pinus podem ser explicados pelo fato de que o pinus apresenta decomposição mais lenta em relação a outros tipos de vegetação, formando uma camada de manta orgânica mais espessa sobre o solo (PULROLNIK et al. 2009; ZANATTA et al. 2013).

Comparando as compartimentalizações das quatro áreas de estudo foi possível verificar que a serapilheira é composta principalmente pelas folhas e acículas das florestas. As folhas apresentaram maior porcentagem no plantio de eucalipto $(83,98 \%)$, seguido das acículas $(77,72 \%)$. Este resultado pode ser explicado devido ao plantio de eucalipto ser jovem, o que ocorre alta taxa respiratória e produção de folhas, logo, ocorre a senescência das mesmas. Já para o plantio de pinus este alto valor de acículas esta associado ao longo tempo de 
decomposição das mesmas e ao acúmulo ao longo dos anos, já que não ocorria a limpeza da área.

$\mathrm{Na}$ fração de galhos a porcentagem maior foi na Mata de Galeria com $20,38 \%$, o CSR com $18,13 \%$, o eucalipto com $11,43 \%$ e o pinus com menor porcentagem 3,42\%. Na Mata de galeria e CSR a diversidade de espécies presentes e a densidade de árvores faz com que a desrama natural ocorra em maior freqüência para evitar a competição entre os indivíduos (SCHNEIDER et al., 1999).

$\mathrm{Na}$ fração casca o pinus representa maior porcentagem, com 4,94\%; a Mata de Galeria e o CSR tiverem resultados próximos, com 3,75\% e 3,68\% respectivamente; e o eucalipto com 3,33\%. Pode-se inferir que esse resultado é devido as três primeiras florestas serem mais velhas apresentando a senescência da casca.

Quanto ao material reprodutivo, a floresta de pinus teve maior valor com $13,82 \%$ devido ao peso das pinhas junto com flores e sementes. Enquanto o CSR teve $2,49 \%$; a mata de galeria $1,74 \%$ e a floresta de eucalipto com $1,17 \%$. A miscelânea observada nas áreas teve um maior valor na área de CSR com 2,23\%; 1,02 na APP, e abaixo de 1\% nas áreas de pinus e eucalipto, com 0,1\% e 0,09\% respectivamente. A maior quantidade de miscelânia no CSR e Mata de Galeria devese a diversidade de espécies vegetais, logo a de animais e insetos também. Embora a fração miscelânia seja a menor, por constituir de matéria orgânica animal, os teores de nitrogênio, fósforo, potássio e enxofre são maiores do que nas outras frações (DOMINGOS et al., 1997).

As florestas necessitam de uma forma para se manterem produzindo, recebendo e depositando, quando mortas, nutrientes. Esse equilíbrio se dá devido a serapilheira depositada, onde ocorre uma ciclagem de nutrientes. Mesmo com espécies diferentes, a serapilheira apresenta um mesmo padrão de composição e quantidade, o que indica uma homogeneidade no equilíbrio dessas florestas serem parecidas.

\section{CONCLUSÃO}

Entre as compartimentalizações da serapilheira, as folhas/acículas são as que apresentam maior porcentagem, seguido de galhos. As frações de material reprodutivo e miscelânea são as de menor representatividade. Todas essas frações contribuem para a manutenção e equilíbrio da floresta.

As florestas seguem um mesmo padrão de produção de serapilheira, sendo a idade da floresta um dos fatores mais importantes para essa produção.

\section{REFERÊNCIAS}

BORÉM, R. A. T.; RAMOS, D. P. Variação estacional e topográfica de nutrientes na serapilheira de um fragmento de Mata Atlântica. Cerne, v. 8, n. 2, p. 42- 59, 2002.

CALDEIRA, M. V. W.; MARQUES, R.; SOARES, R. V.; BALBINOT, R. Quantificação de serapilheira e de nutrientes- Floresta Ombrófila Mista Montana- Paraná. Revista Acadêmica. v. 5, n. 2, p. 101-116, 2007.

CALDEIRA, M. V. W.; VITORINO, M. D.; SCHAADT, S. S.; MORAES, E.; BALBINOT, R. Quantificação de serapilheira e de nutrientes em uma Floresta Ombrófila Densa. Semina: Ciências Agrárias, v. 29, n. 1, p. 53-68, 2008. 
CORRÊA, Robson Schaff. Ciclagem de nutrientes em Eucalyptus dunnii estabelecido no Bioma Pampa. 2011. 99 f. Tese (Doutorado em Engenharia Florestal) - Universidade Federal de Santa Maria, Santa Maria. 2011.

DICKOW, K. M. C.; MARQUES, R.; PINTO, C, B. Lixiviação de nutrientes da serapilheira recém-depositada em sucessão ecológica na floresta Atlântica, litoral do Paraná. Floresta, v.39, n.1, p.145-156, 2009.

DOMINGOS, M.; MORAES, R. M.; VUONO, Y. S.; ANSELMO, C. E. Produção de serapilheira e retorno de nutrientes em um trecho de Mata Atlântica secundária, na Reserva Biológica de Paranapiacaba, SP. Revista Brasileira de Botânica, v. 20, n.1, p.91-96, 1997.

FERREIRA, F. S. O.; CARDOSO, E. Estrutura fotossociológica de campo sujo no município de Catalão- GO. Caminhos de Geografia, v. 14, n.45, p. 110-119, 2013.

FIGUEIREDO FILHO, A.; MORAES, G. F.; SCHAAF, L. B.; FIGUEIREDO, D. J. Avaliação Estacional da deposição de serapilheira em uma Floresta Ombrófila Mista Localizada no Sul do Paraná. Ciência Florestal, v. 13, n. 1, p. 11-18, 2003.

ICMBIO. Instituto Chico Mendes de Conservação da Biodiversidade. Plano de Manejo da Floresta Nacional de Silvânia, Goiás - volume I Diagnóstico. Brasilia. 297 p. 2015.

KLEINPAUL, I. S.; SCHUMACHER, M. V.; KÖNIG, F. G.; KLEINPAUL, J. J. Acúmulo de serapilheira em povoamentos de pinus e eucaliptos no campus da UFSM. In: 9 o Congresso Florestal Estadual do Rio Grande do Sul, 2003, Nova Prata. 9o Congresso Florestal Estadual do Rio Grande do Sul, 2003.

MAMAN, A. P. ; SILVA, C. J. ; SGUAREZI, E. M. ; BLEICH, M. E. Produção e acúmulo de serapilheira e decomposição foliar em Mata de Galeria e Cerradão no sudoeste de Mato Grosso. Revista de Ciências Agro-Ambientais, v.5, n.1, p.71-84, 2007.

PEELL, M. C.; FINLAYSON, B. L.; MCMAHON, T. A. Updated world map of the Köppen-Geiger climate classification. Hydrology and Earth System Sciences, v. 11, n. 5, p. 1633-1644, 2007.

PIOVESAN, G.; SCHUMACHER, M. V.; VIEIRA, M.; LOPES, V. G.; WELTER, C. Deposição de serapilheira em povoamento de pinus. Pesquisa Agropecuária Tropical, v.42, n.2, p. 206-211, 2012.

POGGIANI, F.; SCHUMACHER, M. V. Ciclagem de nutrientes em florestas nativas. In: Gonçalves, José Leonardo de Moraes. Benedetti, Vanderlei (editores). Nutrição e Fertilização Florestal. Instituto de Pesquisas e Estudos Florestais. Cap. 10, p. 287-308, 2000.

PRADO, L. A.; SILVA, M. V. A. Expansão da fronteira e influência da topografia nas mudanças de uso do solo no município de Catalão-Go. Anais XV Simpósio Brasileiro de Sensoriamento Remoto - SBSR, Curitiba, PR, p.2884, 2011. 
PULROLNIK, K.; BARROS, N. F.; SILVA, I. R.; NOVAIS, R. F.; BRANDANI, C. B. (2009). Estoques de carbono e nitrogênio em frações lábeis e estáveis da matéria orgânica de solos sob eucalipto, pastagem e cerrado no Vale do Jequitinhonha MG. Revista Brasileira de Ciência do Solo, v. 33, n.5, p.1125-1136, 2009.

SCHNEIDER, P. R.; FINGER, C. A. G.; HOPPE, J. M. Efeito da intensidade de desrama na produção de pinus elliottii engelm., implantado em solo pobre, no estado do Rio Grande do Sul. Ciência Florestal, v. 9, n.1, p.35-46, 1999.

SCHUMACHER, M. V.; BRUN, E. J.; KÖNIG, F. G.; KLEINPAUL, J. J.; KLEINPAUL, I. S. Análise de nutrientes para a sustentabilidade. Revista da Madeira, n. 83, ano 14, 2004.

SOUZA, M. G. R.; FORSTHOFER, M.; ABREU, M. F.; MARIMON JUNIRO, B. H.; MARIMON, B. S. Comparação da produção de serapilheira entre um Cerrado Sentido Restrito e um Cerradão no Parque Municipal de Bacaba, Nova XavantinaMT. Anais vol. 7. Congresso de Iniciação Científica, Cáceres, MT. 2011.

VIEIRA, M.; SCHUMACHER, M. V. Variação mensal da deposição de serapilheira em povoamento de Pinus taeda L. em área de campo nativo em Cambará do SulRS. Revista Árvore, v.34, n. 3, p.487-494, 2010.

ZANATTA, J. A.; HIGA, R. C. V.; DEDECEK, R. A., GARRASTAZU, M. C., CARDOSO, D. J. Estoques de carbono e nitrogênio em solos florestais e agrícolas na região de Caçador, SC. Documento 256, Boletim EMBRAPA, 2013. 